\title{
Dr. P K Sen- the Bengali Surgeon of the Century
}

\author{
N Hosain \\ Department of Cardiothoracic Surgery, Chittagong Medical College
}

\begin{abstract}
:
Dr Parafulla Kumar Sen, popularly known as $P K$ Sen was a great Bengali surgeon of Twentieth century. Regarded as the founder of cardiothoracic surgery in India, Dr Sen performed the first intracardiac operation of any kind, the first open heart surgery and also the first heart transplantation in this subcontinent. He also made very significant contribution in the development of transmyocardial revascularization, a new technique for aortic arch replacement and described a group of nonspecific vasculitis. Dr P K Sen was born in Kolkata, the then capital of undivided Bengal in 1915. But he is little known in Bangladesh. This article is an attempt to notify the deeds of this Bengali surgeon.
\end{abstract}

(Cardiovasc. j. 2011; 3(2): 254-257)

\section{Introduction:}

There is a bright chapter in the Cardiothoracic surgery history book depicting the achievement \& activities of a Bengali surgeon little known in Bangladesh. One of the most eminent cardiothoracic surgeons of the World, Dr Profulla Kumar Sen (1915-1982), popularly known as P K Sen is respected for his contribution in the development of Cardiothoracic Surgery in India. He had a keen interest in research and in the subsequent clinical application of knowledge gained in the laboratory. His areas of contribution include heart transplantation, transmyocardial acupuncture technique for ischemic myocardium, identifying a group of nonspecific vasculitis and developing a new technique for aortic arch replacement. After many years of work with animal models, on $16^{\text {th }}$ February 1968, P.K. Sen and his team performed the 1 st cardiac transplantation in India and also the 6th in the world. ${ }^{1}$ Though the patient and subsequently a second one soon to follow didn't survive more than a few hours, this attempt was a real success story in those days' standard, competing with the surgeons of South Africa, USA and France.

\section{Biography:}

P.K. Sen was born on 7 December 1915 to a middleclass family at Calcutta, the then capital of undivided Bengal. He graduated from Seth G.S. Medical College, Bombay and then obtained his

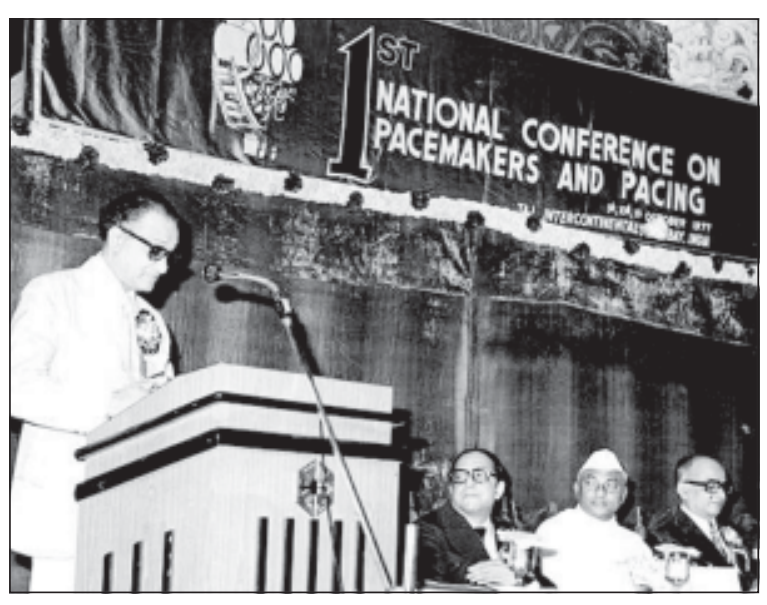

Fig.-1: Dr P K Sen speaking at a conference in 1977.

Masters degree in surgery, with distinction from the University of Bombay. Dr. Sen then joined and held various posts at King Edward Memorial Hospital (KEM), Bombay till the last day of his life. The department of cardiothoracic surgery at KEM was founded by him and now bears his name. In 1954, Sen married Marie Barnes, an American physiologist from Philadelphia. They met in Philadelphia while Sen was working in the laboratory of University of Pennsylvania during $1950-51 .^{2}$

Sen performed the full range of cardiac surgeries possible in his days and pioneered of several procedures in India. He was indeed the founder of cardiothoracic surgery there and was also the first

Address of Correspondence: Dr. Nazmul Hosaim, Associate Professor, Cardiothoracic Surgery, Chittagong Medical College, Chittagong Chittagong, Bangladesh, E-mail: snhosain@gmail.com 
to perform intracardiac operation of any kind. Only Pericardiectomy and Ligation of Patent Ductus Arteriosus had been attempted before him. Beginning with Closed Mitral Commisurotomy ${ }^{3}$ in 1952, P.K. Sen started closing Atrial Septal Defects with the aid of hypothermia and inflow occlusion techniques since 1957, before doing so with the aid of extracorporeal circulation in March 1962. ${ }^{4}$ Once the heart-lung machine became available, other open-heart operations became routine for him.

He was in frequent touch with famous names in cardiovascular surgery including Drs. William Bigelow, Denton Cooley, Norman Shumway, Christian Barnard, Donald Ross, and Sir Brian Barrett-Boyes. ${ }^{1}$ When Sen ventured beyond the subject of surgery, he did so with authority, for he was a Poet, Painter, Musician, Astronomer, Golfer and flyer - acquiring excellence in every field along with surgery. ${ }^{1}$ It is said that he could have achieved excellence if persuaded career in any of these subjects besides Surgery. His paintings were exhibited twice in India and once in the United States. Among his many awards, there were the Vishinskey Medal (USSR) and the Padma Bhushan, the highest award that India conferred on any scientist at that time. After a very bright and successful career, Dr P K Sen breathed his last on $22^{\text {nd }}$ July 1982 at Kolkata.

\section{Heart Transplantation:}

In 1954, conceiving the possibility of heart transplantation, Dr P K Sen and his team began their experiments in mongrel dogs to determine the effect of profound hypothermia. After a long painstaking research Sen concluded that heartlung preparations could be transplanted but decided to await further technical advances before embarking upon transplant experiments. Sen was further encouraged after seeing the work of V.P. Demikhov during his visit to the USSR in 1962. During 1963 and 1964, Sen and his group performed about 100 experiments on dogs to study rejection and to learn the most suitable techniques for heart transplantation. ${ }^{5}$

The astonishing news on 3 December 1967-that Christian Barnard of South Africa had performed the 1st human cardiac transplant-gave a sense of urgency to investigators worldwide who were close to clinical application of what they had learned in the laboratory. As a last step, Sen and his team studied human cadavers for details of the operative anatomy as it pertained to both donor and recipient. Within a month of Christiaan Barnard's first cardiac transplantation procedure, Sen and his colleagues were planning their own. As a suitable recipient, they chose a 27-year-old man. Ironically, this patient had been admitted to their cardiology ward even before Barnard's historic operation and who was still there, suffering from chronic progressive cardiomyopathy, with cardiac failure refractory to medical treatment. So theoretically, at least P K Sen could easily be in the position of Bernard as the first surgeon to perform heart transplantation, had his hands not been tied by the lack of proper legislation. On $16^{\text {th }}$ February 1968, a 20-year-old woman presented at the emergency ward at King Edward Memorial Hospital in an unconscious state after sustaining a severe head injury in a train accident. Bitemporal exploratory burr holes revealed extensive cerebral lacerations and contusions, and the patient's vital signs deteriorated rapidly over the next few hours. Her blood group matched that of the recipient, so she was selected as a donor. Sen and his team performed the first transplantation of India. However, 15 minutes after the patient had been weaned from cardiopulmonary bypass, the right ventricle began to enlarge rapidly and had to be vented, while the left side worked normally.

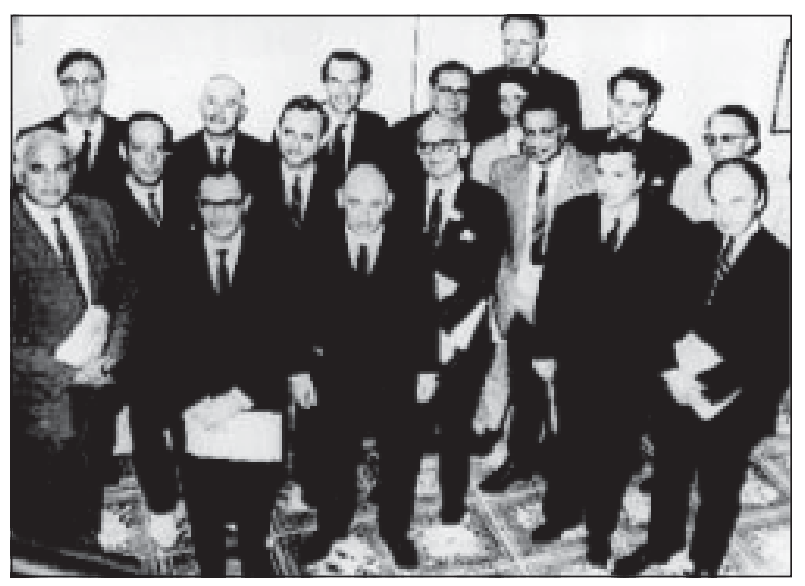

Fig.-2: A group of surgeons, most of whom had done at least one heart transplant, gathered in Cape Town for a symposium in July 1968. Dr. Christiaan Barnard, who arranged the meeting, is $7^{\text {th }}$ from left, in the rear. Dr. Denton Cooley stands tall in the back, while Dr. P.K. Sen is $5^{\text {th }}$ from right. 
Despite all measures the heart stopped functioning 3 hours after the transplantation. ${ }^{6}$

On $13^{\text {th }}$ September the same year, Sen and his team attempted another transplant. In this instance, the recipient was a 22 -year-old man and the donor a 25-year-old woman (again, brain dead). The technique was the same, except that hydrocortisone was used for immunosuppression. This time the heart functioned for 14 hours, before the patient died of anuria. Autopsy showed pulmonary hypertension, multiple pulmonary emboli, and renal tubular damage. ${ }^{7}$ After this, no further transplants were attempted in India for 28 years, because India lacked proper laws concerning definition of brain death and organ donation. Only after 1993, when a proper law came into force, Prof. P. Venugopal at All India Institute of Medical Sciences (AIIMS) performed the 1st successful cardiac transplantation in 1994.

\section{Transmyocardial Acupunture:}

By 1960 Sen turned his attention to the primitive cardiac circulation. Sen and his team explored the reptilian heart, in which the myocardium is supplied chiefly by channels that arise directly from the cavities of the heart, with only a rim at the heart's periphery supplied by coronary vessels. They opened the Russell's viper heart and showed by dye studies that $11 / 12$ ths of the myocardium is supplied by these transmyocardial channels. 12 In higher animals, these channels have nearly disappeared and persist only in rudimentary form, as thebesian circulation: the arteriae and venae cordis minimae. Influenced by his study of the reptilian circulation, Sen went on to pioneer the technique of transmyocardial acupuncture. He 1st reported this technique in a paper read before the Silver Jubilee conference of the Association of Surgeons of India, in December $1964 .{ }^{8}$

Dr. Sen's method consisted of multiple fullthickness acupuncture of the ventricular myocardium, in such a manner as to provide blood flow directly from the ventricles to the myocardium. Because this was an attempt to construct channels as seen in reptiles, he called this his "snake-heart operation." He and his team experimented extensively in animals before proceeding to human beings, and then applied the operation only to the most acute cases. ${ }^{9}$ Several groups tried this technique, with varied results. Dr. Denton Cooley, of the Texas Heart Institute, also tried this technique. In a personal communication with Sen in 1968, he reported its use in patients undergoing prolonged cardiopulmonary bypass during coronary artery surgery. In 1969, Roque Pifarre and colleagues ${ }^{10}$ pronounced myocardial perfusion by transmyocardial acupuncture "a physiologic impossibility." The technique was not much tested in clinical trials, but experimental work to reveal its merits and demerits continued for some time. This concept was revisited in 1981 by M. Mirhoseini and M.M. Cayton ${ }^{11}$ when they proposed creating transmyocardial channels with a laser apparatus. Since then, the technique has been revived as "transmyocardial laser revascularization" and is being used experimentally in combination with gene therapy.

\section{Other Research Works:}

Dr Sen published some original observations on vascular diseases that he grouped under the name nonspecific aortoarteritis ${ }^{12}$. His monograph on this subject has become a standard reference work. ${ }^{13}$ He also contributed to cardiac radiology by experimenting with nuclear isotopes. His other works encompassed vascular pathology, constrictive pericarditis, Ebstein's anomaly and other congenital heart diseases.

\section{Legacy:}

P.K. Sen had a keen interest in experimental and clinical research to discover the basic nature of disease and to apply that knowledge to treatment. He was well ahead of his time, for the transmyocardial laser revascularization of the 1990s was only an extension of his mechanical myocardial acupuncture for the treatment of ischemic heart disease. That Sen performed the world's 6th heart transplant speaks volumes about his quest to be in the forefront. Unfortunately, he was impeded in those early days of cardiac transplantation by the absence of a law on brain death, which meant that donor hearts could be harvested only after they had ceased to beat.

An excellent teacher, Dr. Sen enlivened his lectures with poetry, philosophy, and quotations from the history of medical science. He had a charismatic influence upon his students and 
disciples, who included Drs. R.A. Bhalerao, Sharad Panday, Nitu Madke, S.A. Padmavati, Sudhanshu Bhattacharya, M.S. Valiathan, and Arun Chaukar. His colleagues included Drs. T.P. Kulkarni, G.B. Parulkar, and M.D. Kelkar.

Renowned cardiac surgeon Dr Sudhansu Bhattacharyya was the last Senior Registrar of Dr P K Sen. In a personal communication with the author, he described Dr Sen as a great task master, who made his team members strong mentally and physically. There was no room for complain and one had to manage to run the show. They passed through a very rough and tough life. New ideas were entertained and all felt happy to work with him. In his address as the President of Indian Association of Cardiothoracic Surgeons $2002 \mathrm{Dr}$ Bhattacharyya said, "His great towering personality had magnetized me and attracted me to KEM Hospital. After that there was no second thought or looking back. I worked relentlessly swallowing my pride while Dr P K Sen showered his abuse. Nothing was good enough for him....... Many residents left his services midway. .... This kind of treatment resulted in making me a strongwilled perfectionist. He was my first role model."14

The respect for $\mathrm{P}$ K Sen has reached beyond the arena of cardiothoracic surgeons. Association of Surgeons of India has been organizing Dr. P.K. Sen Memorial Oration ${ }^{15}$ in their annual conference for many years showing their respect and gratitude towards him. Dr Tehempton Udwadia, a contemporary surgeon and former editor Indian Journal of Surgery correctly described Professor Sen as one of the great surgeons of India to whom the prestige and growth of Indian surgery was a matter of passion and pride. The most important message passed on to him was his own determination to reach for the stars as Sen once quoted to him "Udwadia, they build too low who build below the stars".

Through his work \& achievement, this Bengali surgeon of the century reached the level of stars indeed.

\section{Acknowledgements:}

Here go special thanks to Dr Sudhansu Bhattacharyya and Prof Anil G Tendolkar for their invaluable help \& encouragement in writing this article.

\section{References:}

1. Mittal CM. Prafulla Kumar Sen His contributions in Cardiothoracic Surgery. Tex Heart Inst J 2002; 29(1): $17-25$.

2. Parulkar GB. Dr. P. K. Sen-the obituary. Indian J Thorac Cardiovasc Surg 1982;1:92-4.

3. Sen PK, Datey KK. Surgical correction of mitral stenosis. Ind J Med Sci 1955;9:355-64.

4. Parulkar GB, Dhruva AJ, Sen PK. Atrial septal defect. A report of fourteen cases treated surgically. J Postgrad Med 1962; 8:60-6.

5. Sen PK, Parulkar GB, Panday SR, Kinare SG. Homologous canine heart transplantation: a preliminary report of 100 experiments. Indian J Med Res 1965;53:674-84.

6. Symposium on Human Heart Transplantation. Team from Seth Gordhandas Sunderdas Medical College and King Edward Memorial Hospital, Bombay. J Indian Med Assoc 1968;51:542-63.

7. Sen PK. Human heart homotransplantation. Am J Cardiol 1968;22:826-32.

8. Sen PK, Udwadia TE, Kinare SG, Parulkar GB. Transmyocardial acupuncture: a new approach to myocardial revascularization. Proceedings of the Silver Jubilee Conference of the Association of Surgeons of India; December 1964; Bombay, India.

9. Sen PK, Udwadia TE, Kinare SG, Parulkar GB. Transmyocardial acupuncture. A new approach to myocardial revascularization. J Thorac Cardiovasc Surg 1965;50:181-9

10. Pifarre R, Jasuja ML, Lynch RD, Neville WE. Myocardial revascularization by transmyocardial acupuncture. A physiologic impossibility. J Thorac Cardiovasc Surg 1969;58: 424-31.

11. Mirhoseini M, Cayton MM. Revascularization of the heart by laser. J Microsurg 1981;2:253-60.

12. Sen PK, Kinare SG, Kelkar MD, Nanivadekar SA. Nonspecific stenosing arteritis of the aorta and its branches: a study of a possible etiology. Mt Sinai J Med 1972;39:221-42.

13. Sen PK. Non-specific aortoarteritis-a monograph based on a study of 101 cases. Bombay: Tata McGraw Hill; 1972

14. Bhattacharyya S, Presidential address, IACTS Annual Conference, Chennai 2002

15. Dr. P.K. Sen Memorial Oration - 2011 (Internet). Available at :http://www.asiindia.org/AwardsSen\%20Memorial\%20Oration.php 